\title{
A Thrombophilia Family With Protein S Deficiency Due to Protein Translation Disorders Caused By a Leu607Ser Heterozygous Mutation in PROS1
}

\section{Yan-ping Zhang}

Fujian Medical University

Bin Lin

Fujian Medical University

Yuan-yuan Ji

Fujian Medical University

Ya-nan Hu

Fujian Medical University

Xin-fu Lin

Fujian Medical University

Yi Tang

Fujian Medical University

Jian-hui Zhang

Fujian Medical University

Shao-jie Wu

Fujian Medical University

Sen-lin Cai

Fujian Medical University

Yan-feng Zhou

Fujian Medical University

Ting Chen

Fujian Medical University

\section{Zhu-ting Fang}

Fujian Medical University

Jiewei Luo ( $\square$ docluo0421@aliyun.com )

Fujian Provincial Hospital https://orcid.org/0000-0003-4271-4848

\section{Research}

Keywords: protein S, deficiency, PROS1, mutation, vein thrombosis 
Posted Date: July 8th, 2021

DOl: https://doi.org/10.21203/rs.3.rs-680368/v1

License: (c) (1) This work is licensed under a Creative Commons Attribution 4.0 International License. Read Full License

Version of Record: A version of this preprint was published at Thrombosis Journal on September 8th, 2021. See the published version at https://doi.org/10.1186/s12959-021-00316-4. 


\section{Abstract}

Background: Protein S deficiency (PSD) is an autosomal dominant hereditary disease. In 1984, familial PSD was reported to be prone to recurrent thrombosis. Follow-up studies have shown that heterozygous protein S (PROS1) mutations increase the risk of thrombosis. More than 300 PROS1 mutations have been identified; among them, only a small number of mutations have been reported its possible mechanism to reduce plasma protein S (PS) levels. However, whether PROS1 mutations affect protein structure and why it can induce PSD remains unknown.

Methods: The clinical phenotypes of the members of a family with thrombosis were collected. Their PS activity was measured using the coagulation method, whereas their protein $\mathrm{C}$ and antithrombin III activities were measured using methods such as the chromogenic substrate method. The proband and her parents were screened for the responsible mutation using second-generation whole exon sequencing, and the members of the family were verified for suspected mutations using Sanger sequencing. Mutant and wild type plasmids were constructed and transfected into HEK293T cells to detect the mRNA and protein expression of PROS1.

Results: In this family, the proband with venous thrombosis of both lower extremities, the proband's mother with pulmonary thrombosis and venous thrombosis of both lower extremities, and the proband's younger brother had significantly lower PS activity and carried a PROS1 c. 1820T > C:p.Leu607Ser heterozygous mutation (NM_000313.3). However, no such mutations were found in family members with normal PS activity. The PS expression in the cell lysate and supernatant of the Leu607Ser mutant cells decreased, while mRNA expression increased. Immunofluorescence localization showed that there was no significant difference in protein localization before and after mutation.

Conclusions: The analysis of family phenotype, gene association, and cell function tests suggest that the PROS Leu607Ser heterozygous mutation may be a pathogenic mutation. Serine substitution causes structural instability of the entire protein. These data indicate that impaired PS translation and synthesis or possible secretion impairment is the main pathogenesis of this family with hereditary PSD and thrombophilia.

\section{Background}

Protein S (PS) is a vitamin K-dependent plasma glycoprotein that is mainly synthesized by hepatocytes or macrophages [1]. Forty percent of PS is free and has anticoagulant activity, while $60 \%$ of PS is bound to C4b and has no activity [2]. On the one hand, PS exerts an anticoagulant effect mainly by serving as a cofactor of activated protein C (APC) to promote the inactivation of factor V (FV) a and FVIIla [3]. On the other hand, PS also serves as a cofactor of tissue factor pathway inhibitor (TFPI), which inhibits the activity of tissue factors by promoting the binding interaction of TFPI and FXa [4]. Hereditary protein S deficiency (PSD) is an autosomal dominant hereditary disease, which may be caused by genetic and acquired factors [5]. It is classified into three subtypes: Type I (total PS, free PS levels, and PS activity are 
decreased), type II (total PS and free PS levels are normal, but PS activity is decreased), and type III (total PS level is normal, but free PS level and PS activity are decreased) [6]. There is no significant difference among these three types of clinical manifestations, which are only identified by laboratory testing; $95 \%$ of patients with PSD develop type I and type III PSD [7].

As of September 6, 2021, there are more than 360 mutations in PSD-related genes in the Human Gene Mutation Database (HGMD) (http://www.hgmd.org). There are 276 types of missense/nonsense, 48 types of splicing, 4 types of regulatory, 54 types of small deletions, 25 types of small insertions, 6 types of small indels, 28 types of gross deletions, 7 types of gross insertions, as well as complex repeats that have not yet been identified. The most common causes of PSD are missense or nonsense substitutions, followed by splice site mutations, small or large repeats, insertions, or deletions [8]. The main clinical manifestations of most patients with heterozygous mutations in the protein $\mathrm{S}$ gene (PROS1) are lower extremity deep venous thrombosis and pulmonary embolism [9]. PROS1 mutations are associated with an increased risk of venous thrombosis [10], and some reports suggest that $P R O S 1$ variants increase the risk of arterial embolism, such as cerebral infarction and myocardial infarction [11]. About half of patients with PSD develop symptoms before the age of 55 , while some of them have no complications for the rest of their lives [12]. In the past, we detected a new mutation in PROS1 in a family prone to thrombosis, which had not been previously reported. In this study, we discuss the pathogenicity and pathogenesis of this mutation.

\section{Methods And Materials}

\section{Research subjects}

The 16-year-old female proband (III5), of Han nationality, complained of "swelling and pain in the left lower limb for 3 days". She was in good health and had no bad lifestyle-related habits, such as, smoking, drinking etc. Among the family members, her mother (II8) had a history of bilateral deep venous thrombosis of the lower extremities and pulmonary embolism, and her parents were from nonconsanguineous marriages. Physical examination showed that the left lower limb of the proband had edema, especially on the dorsal foot, shank, and thigh. There were no obvious varicose veins, hyperpigmentation, skin ulceration, palpable nodules, or deep vein tenderness with a positive Homan's sign. The circumference of both lower limbs was measured and was as follows: $15 \mathrm{~cm}$ above the left patella, $44 \mathrm{~cm} ; 15 \mathrm{~cm}$ above the right patella, $39 \mathrm{~cm} ; 15 \mathrm{~cm}$ below the left patella, $39 \mathrm{~cm}$; and 15 $\mathrm{cm}$ below the right patella, $36 \mathrm{~cm}$. The rest of the physical examination showed no obvious abnormalities. Relevant examinations were performed after hospital admission.

At the age of 39, II8 had complained of "distension and pain of the left lower limb for 2 days" in another hospital. She was in good health and had no special bad habits. Physical examination revealed swelling of the left lower limb. She was diagnosed with "deep venous thrombosis of the left lower limb" and was treated with anticoagulation and thrombolysis. After that, she improved and was discharged from the hospital and took anticoagulants regularly for a long time. A year ago, she visited the hospital again due 
to "sudden chest pain with loss of consciousness" and was diagnosed with "pulmonary embolism." The father of II8 (I1) and her two older sisters (II 3 and 4) all died of pulmonary embolism and deep vein thrombosis (DVT) of the lower limbs. To date, no thrombosis has been found in other family members.

\section{Methods}

Clinical phenotype detection Clinical phenotypes and clinical biochemical indicators were collected from the proband and her related family members. Clinical biochemical indexes included PS activity, as measured using the coagulation method and the activity of protein C (PC) and antithrombin III (AT-III), as measured using the chromogenic substrate method, blood routine, coagulation function, and biochemistry.

Extraction of genomic DNA Peripheral blood $(8 \mathrm{~mL})$ of the proband and peripheral blood $(2 \mathrm{~mL})$ of each family member were collected in ethylenediaminetetraacetic acid anticoagulant tubes, and genomic DNA of the proband and her family members was extracted using the QIAGEN DNA Blood Mini Kit (Cat\# 51106, QIAGEN Co., Ltd., Shanghai, China).

Location and screening strategy of mutant genes The TargetSeq ${ }^{\circledR}$ liquid probe hybridization and capture technique independently developed by Igen iGeneTech ${ }^{\circledR}$ (Beijing, China) was used to establish a genomic DNA library and capture the promoter and exon regions (16.06 Mbp) of 5,081 genes related to genetic diseases. Paired end 150 bp sequencing was performed using the Illumina X10 or NovaSeq 6000 platform. The captured target genes were PROS1 and Serpin family C member 1 (SERPINC1). Based on the results of BAM alignment with the genome reference sequence, single-nucleotide variants and indels in the samtools, GATK, and ANNOVAR sequencing results were used to remove the variation sites with intermediate frequency higher than 0.01 in ExAC, gnomAD, iGeneTechDB (local database with more than 10,000 samples), benign and likely benign mutations in ClinVar, and synonymous_variant mutations in the Human Genome Variation Society. Combined with the exon sequencing data of the parents, the sources of mutation were annotated and divided into three types: those from the father, from the mother, and suspected to be new mutations. The Hemostasis Thrombosis Expert Panel of the OMIM Phenotypic Series-PS188050 and CLINGENE were used to search for genes. Mutations from the father were excluded (the mutations from the mother and the suspected new mutations were retained), and two mutations in SERPINC1 and PROS1 were obtained. Sorting Intolerant from Tolerant (SIFT, http://sift.jcvi.org/), Polymorphism Phenotyping (PolyPhen-2, http://genetics. Bwh.harvard.edu/ppH2/) and Mutation Taster (http://mutationtaster.org/) were used to predict the pathogenicity and harmfulness of the mutations. The upper and downstream positions of the sequence of the target mutation site were designed using Premier 5.0, and the target area was amplified. The corresponding suspected pathogenic mutations were verified by Sanger sequencing using the ABI3500Dx platform. The amplified fragment length of c. 1820T > C:p, the Leu607Ser sequence of the mutation point in PROS1 (NM_000313.3), was 498 bp. The primers F: CTGGCTGGGATAGCCAAATGA and R: CTTGCTTATATTGAATCTTTGCTCTGC were used for amplification (melting temperature, $62.5^{\circ} \mathrm{C}$ ). The amplified fragment length of c.883G > A:p, the Val295Met sequence of SERPINC1 (NM_000488.3), was 407 bp. The primers F: 
CTTGCAGCTGCTCCTTCAAACT and R: TGTCTTGTGTCAATAACTATCCTCCTA were used for amplification (melting temperature, $61^{\circ} \mathrm{C}$ ). Synbio Technologies Co., Ltd. (Suzhou, China) synthesized all primers.

\section{Construction and identification of PROS1 wild type (WT) and p.Leu607Ser mutant plasmids}

The plasmid synthesis scheme is shown in Fig. 4a. pcDNA3.1-3×Flag-C was used as the expression vector to synthesize PROS1 with a Kpnl/Xhol cleavage site. The WT plasmid 1 (PC DNA 3.1-ProS1 WT-3 $\times$ Flag-C) and the mutant plasmid 2 (pcDNA3.1-PROS1 mut-3×Flag-C) were constructed, both with a $\mathrm{Kpnl} /$ Xhol restriction enzyme site. The mutant plasmid 2 contained the $1820 \mathrm{~T}>\mathrm{C}$ mutation in PROS1. Target genes were amplified and sequenced. The cloning of PROS1 (WT) and PROS1 (1820T > C) and the synthesis of related polymerase chain reaction (PCR) primers were performed by Wuhan Gene Create Biological Engineering Co. Ltd(Wuhan, China).

\section{Cell transfection}

HEK293T cells were digested and collected using trypsin, and the cells were placed into a $10 \mathrm{~cm}$ petri dish at a density of $1-2 \times 10^{7}$ cells/plate in an appropriate complete culture medium. After adhesion, the total area of the cells reached $80 \%-90 \%$ confluence. According to the conditions of cell adhesion, cells were incubated at $37^{\circ} \mathrm{C}$ in an incubator containing $5 \% \mathrm{CO}_{2}$ for $8-24 \mathrm{~h}$, and transient transfection was started after the cells were completely adhered. According to the instructions for TurboFect (R0531, Thermo, Massachusetts, USA), TurboFect-DNA Mix was prepared and mixed with DNA plasmids (10 $\mu \mathrm{g} /$ PROS1 WT, mutant, or control plasmid $+5 \mu \mathrm{g}$ green fluorescent protein [GFP]) and $30 \mu \mathrm{L}$ TurboFect in $1000 \mu \mathrm{L}$ Opti-Medium. After incubation at room temperature for $15 \mathrm{~min}$, TurboFect-DNA Mix was added to the petri dish. After $12 \mathrm{~h}$, the complete medium was changed, and HEK293T cells were cultured for 48 $\mathrm{h}$. Cells were observed to be in good condition by microscopy and the culture medium was collected for further evaluation.

\section{Quantitative real-time (qRT)-PCR detection}

HEK293T total RNA was extracted according to the TriPure Isolation Reagent kit (11667165001, Roche, Shanghai, China), and the difference in the PROS1 transcription levels was detected by reverse transcription and qRT-PCR. The first chain of cDNA was synthesized according to HiFiScript (CW2020M, CWBIO, Beijing, China). The reaction system contained $2.5 \mathrm{mM}$ dNTP Mix, $4 \mu \mathrm{L}$; primer mix, $2 \mu \mathrm{L}$ (primers in Table 1); RNA Template, $7 \mu \mathrm{L}$; 5× RT Buffer, $4 \mu \mathrm{L}$; 1× dithiothreitol, $0.1 \mathrm{M}, 2 \mu \mathrm{L} ; 10 \mathrm{mM} \mathrm{HiFiScript,} 200 \mathrm{U} /$ $\mu \mathrm{L}$; and RNase-free water, $20 \mu \mathrm{L}$. After mixing the liquid using a vortexer, the tube was centrifuged for a short time. The product was incubated at $42^{\circ} \mathrm{C}$ for 50 min and at $85^{\circ} \mathrm{C}$ for $5 \mathrm{~min}$. The cDNA obtained by reverse transcription was diluted 20-fold, and 40 RT-qPCR cycles were performed in a Roche LightCycler 480 (Roche, Beijing, China).

\section{Western blot detection}


HEK293T cells were cultured, lysed, total protein was extracted, and PROS1 expression was detected. Protein samples were separated using electrophoresis and then wet transferred to a polyvinylidene fluoride (PVDF) membrane, soaked in $5 \%$ skim milk prepared in Tris-buffered saline with $0.1 \%$ Tween ${ }^{\circledR} 20$ (TBST), and sealed at room temperature for $1 \mathrm{~h}$. Next, the membrane was washed once and anti-protein S antibody (97387, Abcam, UK, 1: 500) or actin antibody (ab8227, Abcam, UK, 1: 5000) was added. The Flag antibody (F3165, Sigma, USA, 1:500), diluted with $5 \%$ bovine serum albumin (BSA), was added to the membrane overnight at $4{ }^{\circ} \mathrm{C}$, and the membrane was washed thrice. Horseradish peroxidase-labeled secondary antibodies (goat anti-rabbit IgG, 1:2,000 or goat anti-mouse $\lg$ 1:2,000, diluted with 5\% BSA, ab6721 and ab6789, respectively, Abcam, UK) were added to the membrane and then incubated in a shaker at room temperature for $1 \mathrm{~h}$. The PVDF membrane was washed with TBST five times and with $\mathrm{ddH}_{2} \mathrm{O}$ once before exposure.

\section{Enzyme linked immunosorbent assay (ELISA) of PROS1 in HEK293T cell lysates and cell supernatants}

According to the instructions of the Human Protein S ELISA Kit (ab190808, Abcam, UK), the working standard liquid was prepared, and PROS1 expression in HEK293T cell lysates and cell supernatant was detected. A microplate reader (Varioskan Lux, Thermo, Massachusetts, USA) was used to measure the optical density at $450 \mathrm{~nm}$ immediately after the substrate solution was added to stop the reaction. A standard curve was created and PROS1 levels in the sample were calculated.

\section{Immunofluorescence localization experiment}

After being fixed, permeabilized, and blocked, the transfected HEK293T cells were incubated at $4{ }^{\circ} \mathrm{C}$ overnight with the PROS1 primary antibody (diluted 1:200). The transfected HEK293T cells were rinsed with phosphate-buffered saline (PBS) thrice, the fluorescent secondary antibody (diluted 1:500) was added and incubated at room temperature in the dark for $2 \mathrm{~h}$, rinsed with PBS thrice, and stained with 4, 6diamidino-2-phenylindole. The transfected HEK293T cells were incubated at room temperature for 5 min and rinsed twice with $1 \times$ PBS for 3 min each time. A laser confocal microscope (Nikon A1, Shanghai, China) was used to capture images.

\section{Statistics}

Experimental data were statistically analyzed using GraphPad Prism 6.02. An unpaired $t$-test was used to compare the two groups. The mean value was expressed as the mean \pm standard error of the mean (SEM), and $p<0.05$ indicated that the difference was statistically significant.

\section{Results}

\section{Clinical phenotypes}

The 16-year-old proband (III5) was examined for blood coagulation function after admission (Table 2). The indices related to blood coagulation increased significantly, including the prothrombin time (PT, 13.3 
s), international normalized ratio (INR, 1.17), fibrinogen degradation product (FDP, $57.2 \mu \mathrm{g} / \mathrm{mL}$ ), and Ddimer levels $(25.8 \mathrm{mg} / \mathrm{L})$. Color Doppler ultrasound of the lower limb vein showed thrombosis of the left external iliac vein and deep vein of the left lower limb. Digital subtraction angiography (Figure 1) showed a filling defect in the distal left superficial femoral vein without development and a filling defect of the distal left wall of the left inferior vena cava, indicating thrombosis. PS activity was $<16 \%$ and was significantly decreased, while the PC and AT-III activities were normal; thus, it was considered asthrombosis caused by PSD. The mother of the proband (II8), 42 years old, had a history of recurrent venous thrombosis. For the first time, when lower limb swelling and pain occurred, coagulation function was checked (Table 2), showing that the indices related to blood coagulation were significantly increased. PT was $14.7 \mathrm{~s}$, INR was 1.37, activated partial thromboplastin time was $101.6 \mathrm{~s}$, and thrombin time (TT) was $60 \mathrm{~s}$. Color Doppler ultrasound showed that the inner diameter of the left common femoral vein, superficial femoral vein, deep femoral vein, popliteal vein, and peroneal vein were widened, and the left common femoral vein had a solid echo. Color Doppler flow imaging (CDFI) showed a small number of short-strip blood flow signals in the upper segment of the superficial femoral vein, suggesting DVT of the left lower extremities. Computed tomographic angiography (CTA) (Figure $2 f-n$ ) of the lower limbs showed a low-density filling defect in the common iliac vein, external iliac vein, femoral vein, and popliteal vein lumen, a blurred deep vein of the lower limb, and swelling of the soft tissue of the left lower limb. She was considered to have "deep venous thrombosis of the left lower limb." The second time, 2 years later, when chest pain occurred, CTA (Figure 2a-e) showed a low-density filling defect in the distal left and right pulmonary arteries and bilateral pulmonary artery branches, suggesting pulmonary embolism. Color Doppler ultrasound showed hypoechoic filling in the lower part of the left superficial femoral artery and left popliteal vein. CDFI showed a small number of irregular blood flow signals, suggesting that the deep vein of the left lower extremity and the right popliteal vein were partly recanalized after thrombosis. PS activity was less than $16 \%$ and the activity of AT-III and PC was normal, so it was suspected that PSD caused thrombosis in 118 many times. The 13-year-old younger brother of the proband (III6) had no history of thrombosis. His PS activity was $16.7 \%$ and the PC and AT-III activities were normal; thus, he was diagnosed with PSD. His TT was $30.9 \mathrm{~s}$, which was obviously higher than the normal value. The family was investigated, and a pedigree map of the genetic family was drawn (Figure 3a).

\section{Screening for a thrombophilia gene mutation}

The members of the family were analyzed by whole exon sequencing, and two mutation sites (Figure 3b-

e) were identified in proband III5. One was a heterozygous mutation of exon 14 in PROS1 (NM_000313.3): c.1820T>C(p.Leu607Ser); the transformation from TTG to TCG was not recorded in the ClinVar and HGMD databases. Thus, this is a newly discovered mutation, and its pathogenicity is unclear.

The other was a heterozygous mutation of exon 3 in SERPINC1 (NM_000488.3): c.883G > A (p.Val295Met) (rs201381904). This mutation has not been recorded in the ClinVar and HGMD databases, and its pathogenicity is not clear. According to SIFT [13] and PolyPhen-2 [14] scores, the PROS1 mutation SIFT score is 0 , PolyPhen-2 score is 1, and Mutation Tester [15] predicts that protein function is 
moderately affected. The SERPINC1 mutation SIFT score was 0.036, and the PolyPhen-2 score was 0.996. The lower the SIFT score, the greater the harm and the closer the PolyPhen-2 score to 1, the stronger the pathogenicity. The PROS1 L607S heterozygous mutation and SERPINC1 V295M heterozygous mutation were identified in II8, and a PROS1 L607S heterozygous mutation was also identified in III6. Except for the heterozygous mutation V295M carried by II1, there were no L607S and V295M mutations in other family members.

\section{Cloning of PROS1 WT and p.Leu607Ser gene mutations}

The PROS1 WT and PROS1/p.Leu607Ser cloning and eukaryotic expression vectors were successfully constructed. Fragments of WT PROS1 and mutant PROS1/pLeu607Ser digested by Kpnl/Xhol were approximately $1138 \mathrm{bp}$, which was consistent with plasmid design. The constructed vectors were verified by sequencing and transfected successfully into HEK293T cells (Figure 4 c).

\section{Localization of WT PROS1 and its mutants in cells}

The localization of WT and mutant PROS1 was detected by immunofluorescence (Figure 5), which showed that PROS1 was distributed in the interior of the cells. Because the protein is a secretory protein, there was no significant difference in intracellular fluorescence localization before and after introduction of the PROS1 1820T > C mutation.

\section{Expression of WT PROS1 and its mutants in HEK293T cells}

The relative mRNA expression of the WT (PROS1-WT) and p.Leu607Ser mutant (PROS1-MUT) PROS1 in HEK293T cells was detected using qRT-PCR. The difference between the PROS1 mRNA expression groups was compared to that of actin (Figure 6b) as an internal reference when there was no significant difference in transfection efficiency among groups (Figure 6a). PROS1 mRNA expression was significantly upregulated with the PROS1 1820T > C mutation $(p<0.05)$. GFP was used as an external reference (Figure 6c) to compare the difference between the PROS1 mRNA expression between groups. Again PROS1 mRNA expression was significantly upregulated with the PROS1 1820T>C mutation $(p<0.01)$. PS expression (Figure $6 \mathrm{~d}$ ) in the cell supernatant and lysate was detected by western blotting. PROS1 expression was significantly downregulated with the mutation. At the same time, PROS1 expression in the supernatant of the cell culture medium and cell lysate was detected using ELISA (Figure $6 e, f)$. PROS1 expression levels in the culture medium supernatant and cell lysate of the p.Leu607Ser mutant group was significantly lower than that of the WT group, which was consistent with the results of western blotting.

\section{Discussion}

In this study, the proband (III5) was a 16-year-old young woman who developed deep venous thrombosis of the left lower limb without exposure to other risk factors, which was suspected to be caused by familial heredity. Therefore, the whole exon of III5 was sequenced using next generation sequencing, and a 
suspicious variation in two genes was identified. One was SERPINC1 c.883G > A (p.Val295Met), resulting in the substitution of methionine for valine located at 1q25.1, and containing nine exons, which encoded AT-III. The mutation of a single base leads to AT-III deficiency, which causes the plasma AT-III levels and activity of patients to obviously decrease[16]. Hereditary AT deficiency is autosomal dominant, and thrombosis caused by hereditary AT deficiency is usually more serious than PROS1 and PROC mutations [17]. The AT-III plasma levels in the members of this family were normal, which ruled out the diagnosis of hereditary AT deficiency. The other mutation was PROS1 c. 1820T > C (p.Leu607Ser). The transformation from TTG to TCG resulted in the replacement of leucine with serine. PROS1 is located near the centromere of chromosome 3 (3q11.1); it contains 15 exons and encodes PS [18]. From the $\mathrm{N}$ terminal to the $\mathrm{C}$-terminal, there is a $\mathrm{Y}$-carboxyl glutamate domain, a region sensitive to cleavage by thrombin, four domains homologous to epidermal growth factor, and a region homologous to sex hormone binding globulin (SHBG). SHBG contains two tandem laminin G regions (LG1 and LG2) [19]. Mutations in PROS1 are a risk factor for thrombosis in Asian populations and repeated spontaneous DVT and pulmonary embolism without obvious reasons are the most common symptoms [20]. Whether individuals with PROS1 mutations have thrombosis greatly depends on the interaction between genes and the interaction between genes and the environment. However, compared to individuals without gene mutations, the risk of thrombosis with gene mutations is 2-11 times higher [21]. Mutations in PROS1 lead to decreased PS levels and activity in patients and lead to PSD, which reduces the ability of auxiliary APC to inactivate FVa and FVIla, resulting in thrombosis. For example, a missense PROS1 mutation (Gly222Arg) has been identified in a patient with pulmonary embolism, which causes PS activity to decrease to 5.0\% [22].The PS activity of several codon mutations near L607, such as Ser627fs, Ser627 ins101fsX34 (acc HGMD nomenclature), p.Ala536Val, p.Asn583His, p.Thr617lle, p.Asp624His, and p.Cys666Ser (acc HGVS nomenclature) are all less than $40 \%$, and the lowest is $12 \%$, suggesting that mutation of the corresponding domain causes serious functional defects [23]. The diagnosis of hereditary PSD is generally based on clinical manifestations, plasma PS levels, activity detection, and gene detection[24].

The elder sister and father of 118 died of pulmonary embolism, so there was an obvious genetic tendency in this family. The L607S mutation in III5 and III6 was derived from II8, which was consistent with autosomal dominant hereditary disease and could be diagnosed as hereditary PSD. Although not every patient with PSD has a clinical phenotype, similar to III6, it will obviously increase the risk of thrombosis, especially in patients with heterozygous mutations and PS activity less than $30 \%$ [25]. The occurrence of clinical phenotypes is related to age, sex, and mutation type [26]. There are more male patients with hereditary PSD than female patients with hereditary PSD, but the peak age in females is younger, which is due to the influence of hormones and risk factors, such as trauma, surgery, and oral contraceptives [27]. At present, III6 is a 12-year-old male, but thrombosis is likely to occur with increased age. Coagulation function and venous ultrasound examination should be regularly followed up, and anticoagulant therapy may be administered when appropriate. If PROS1 occurs as a homozygous mutation, the prognosis is poor and the child may die of fulminant purple spot caused by severe PSD in the neonatal period [28]. Similar to the results of an animal experiment, explosive bleeding in 
PROS1 -/-homozygous mice is observed in mice with PROS1 knockout at the embryonic stage. PROS1-/+ heterozygous mice survive to adulthood, but different degrees of vascular injury and dysplasia are observed [29]. At the same time, the level of PROS1 and the activity of auxiliary APC are detected, which are significantly lower than those of WT mice [29]. To verify whether the pathogenicity of PROS1 L607S was consistent with the phenotype observed, plasmids carrying the L607S mutation or WT were constructed and transfected into HEK293T cells. After the PROS1 1820T > C mutation was introduced, PROS1 mRNA expression was obviously upregulated, while PROS1 expression was obviously downregulated in the cell lysate and supernatant. Immunofluorescence localization showed that the protein was distributed in the cell interior, which indicated that the missense mutation did not affect PROS1 mRNA expression, but PS expression and secretion was obviously decreased.

This may be because the mutated residues affect the level of translation and post-translation modification, resulting in disordered protein processing and secretion, which is the main molecular disease mechanism of most missense and other mutations in genetic diseases [30]. In humans and other mammals [31, 32], a comparison between Leu607 of PS and the adjacent flanking structures of PS show that this site is highly conserved (Figure 7). Further analysis of other substitutions was performed on the bases at this site, and Alamut Visual Plus software was used to construct the different variant bases. The substitution of Leu by Trp at codon 607 forms a termination codon. The harmfulness of L607Y was consistent with the Mutation Taster analysis and L607S prediction; L607Y was harmful and moderately affected protein function. In addition, $\mathrm{L} 607 *$ might produce a truncated protein, which was predicted to cause disease. Therefore, it was concluded that protein synthesis and secretion might be affected by the Leu607 conserved site. The Leu607 conserved site plays a key role in the structure and conformation of SHBG and may be important in the PS anticoagulant effect; about half of the PROS1 mutations in the LamG domain involve the acquisition and loss of residues with unique physical and chemical properties, such as cysteine, proline, and glycine, which directly affect PS function [33]. Because most of the mutant residues are hydrophobic, changes in these residues may affect protein folding and secretion [34].

In a PSD family, COS-7 cells were transfected with plasmids containing the D38Y and P626L mutant genes; the PS level and activity of D38Y and P626L mutants is significantly decreased [35], which is consistent with the results of this study. In this study, the hydrophobic amino acid Leu at position 607 was replaced by the polar neutral amino acid Ser. While Ser itself has no charge, its side chain has one more free hydroxyl group than Leu in structure, which is easily phosphorylated by protein kinase. Phosphorylation is the most important post-translational modification and has the greatest effect on the local and overall structural changes in proteins; most phosphorylation occurs on serine residues [36]. The phosphate group formed after phosphorylation of the mutated Ser607 may form hydrogen bonds or salt bridges with the adjacent Lys609, making the local structure compact, which may change the overall conformation of the protein and the interaction between proteins to regulate function [37]. The mutant (https://swissmodel.expasy.org/interactive/7J8pZH/models/) and WT PROS1 (https://swissmodel.expasy.org/interactive/HxBw4h/models/) homologous proteins were 
constructed using the Swiss Model [38], and the characteristics of the advanced structure were observed. The number of amino acid residues in the $\mathrm{Ca}^{2+}$ region of the mutant protein was one less than that of the WT protein, which might be due to the change in local protein structure caused by Ser phosphorylation, leading to a decrease in the binding of PS to other proteins, decreased PS activity, and anticoagulant dysfunction. $\mathrm{Ca}^{2+}$ regulates the binding of the $\mathrm{C}$-terminal SHBG region of bound PS to $\mathrm{C} 4$ binding protein (C4BP)[39]. Both LG1 and LG2 are involved in PS binding to C4BP, showing anticoagulant activity independent of APC [40]. If PS residues Lys423, Lys427, and Lys429 are replaced by other polar amino acids, the binding force between PS and C4BP is reduced by 5-10-fold. Insertion of alanine at position 611 leads to the loss of binding to C4BP [41], which leads to a decrease in anticoagulant function. The anticoagulant activity of free PS through the tissue factor pathway inhibitor (TFPI) is also through the combination of SHBG and TFPI, which further promotes the interaction between TPFI and FX a, thus inhibiting the activity of tissue factor [2]. LG1 and LG2 are necessary for the binding of SHBG and TFPI, but LG1 plays a major role [42]. A R474C mutation leads to PS secretion disorder and intracellular degradation, resulting in type I PSD[43]. By constructing mutant transfected cells, the R474C mutant reduces PS secretion by eight-fold and shortens the half-life of radioactive markers [43]. This might be due to a change in local protein folding. Protein misfolding leads to stagnation in Golgi cells, while unfolded proteins remain in the endoplasmic reticulum cavity for a long time due to molecular chaperone activity. Then, the mechanism of endoplasmic reticulum-associated protein degradation is initiated, which leads to the decomposition of related proteins in cells [44].

\section{Conclusions}

In this study, a heterozygous mutation of PROS1, c.1820T > C:p.Leu607Ser, was identified as a pathogenic mutation that caused disorderly PS translation, synthesis, and secretion or intracellular degradation, and finally led to a decrease in PS levels and activity, resulting in PSD. Heterozygous mutation of PROS1 c.1820T > C:pLeu607Ser was familial.

\section{Abbreviations}

PS: protein S

PROS1: protein S gene

PSD: protein S deficiency

SERPINC1: Serpin family C member 1

TFPI: tissue factor pathway inhibitor

APC: activated protein C

qRT-PCR: quantitative real-time-polymerase chain reaction 
DVT: deep vein thrombosis

PC: protein C

AT-III: antithrombin III

WT: wild type

PVDF: polyvinylidene fluoride

BSA: bovine serum albumin

ELISA: Enzyme linked immunosorbent assay

PBS: phosphate-buffered saline

PT: prothrombin time

INR: international normalized ratio

FDP: fibrinogen degradation product

TT: thrombin time

CDFI: Color Doppler flow imaging

CTA: Computed tomographic angiography

SHBG: sex hormone binding globulin

LG: Iaminin $\mathrm{G}$ regions

C4BP: C4 binding protein

\section{Declarations}

Ethics approval and consent to participate: All procedures were performed in accordance to the tenets of the Declaration of Helsinki and the study was approved by the Ethics Committee of Fujian Provincial Hospital, Fuzhou, China. All participants and legal guardians of the minors involved in the present study provided written informed consent.

Consent for publication: Each subject has a signed consent form.

Availability of data and materials: The datasets used and/or analyzed during the present study are available from the corresponding author upon reasonable request.

Competing interests: The authors have no conflicts of interest to declare. 
Funding: This work was supported in part by grants from the National Natural Science Foundation of China (No. 81874379), Fujian Province Natural Science Fund Project (2020J011064). In addition, the clinical studies were supported by the construction project of Zhang Xuemei's Academic Inheritance Studio of Famous and Aged Chinese Medicine Experts in Fujian Province, and the Special Research Foundation of the Fujian Provincial Department of Finance (No. 2020-500\#, 822\#), China.

Authors' contributions: Collection, data analysis, and drafting of the article: YPZ, BL, YYJ and YNH. Collection: YT, JHZ and SJW. Design, supervision, and editing of the manuscript: JWL and ZTF. Provision of the table and figures: YNH. Study supervision: SLC and YFZ. All authors have read and approved the final manuscript.

\section{Authors' information}

Yan-ping Zhang, Email: zyp373906196@163.com

Bin Lin, Email: 1057925551@qq.com

Yuan-yuan Ji, Email: 2248918828@qq.com

Ya-nan Hu, Email: 602708462@qq.com

Xin-fu Lin, Email: xinfulin1974@163.com

Yi Tang, Email: 411601072@qq.com

Jian-hui Zhang, Email: 1940217761@qq.com

Shao-jie Wu, Email: 412421740@qq.com

Sen-lin Cai, Email: 563731475@qq.com

Yan-feng Zhou, Email: 294790439@qq.com

Ting Chen, Email: cttc1990@126.com

Jie-Wei Luo, Email: docluo0421@aliyun.com

Zhu-Ting Fang, Email: 470389481@qq.com

\section{References}

1. Dahlbäck BJSit. hemostasis: Vitamin K-Dependent Protein S: Beyond the Protein C Pathway. 2018, 44:176-184.

2. Gierula M, Ahnström JJJot. JTH h: Anticoagulant protein S-New insights on interactions and functions. 2020, 18:2801-2811. 
3. Dahlback B. The tale of protein S and C4b-binding protein, story of affection. Thromb Haemost. 2007;98:90-6.

4. Hackeng T, Seré K, Tans G, Rosing JJPotNAoSotUSoA. Protein S stimulates inhibition of the tissue factor pathway by tissue factor pathway inhibitor. 2006, 103:3106-3111.

5. Wypasek E, Undas, AJAic. University emooWM: Protein C and protein S deficiency - practical diagnostic issues. 2013, 22:459-467.

6. Wypasek E, Karpinski M, Alhenc-Gelas M, Undas AJJog. Venous thromboembolism associated with protein S deficiency due to Arg451* mutation in PROS1 gene: a case report and a literature review. 2017, 96:1047-1051.

7. Espinosa-Parrilla Y, Morell M, Souto J, Tirado I, Estivill X, Sala N. Protein S gene analysis reveals the presence of a cosegregating mutation in most pedigrees with type I but not type III PS deficiency. Hum Mutat. 1999;14:30-9.

8. Mrozek M, Wypasek E, Alhenc-Gelas M, Potaczek DP, Undas A. Novel Splice Site Mutation in the PROS1 Gene in a Polish Patient with Venous Thromboembolism: c.602-2delA, Splice Acceptor Site of Exon 7. Medicina. 2020;56:485.

9. Lipe B, Ornstein DJC. Deficiencies of natural anticoagulants, protein C, protein S, and antithrombin. 2011, 124:e365-368.

10. Chan N, Cheng C, Chan K, Wong C, Lau K, Kwong J, Chan N, Wong W, Chow E, Wong M, et al: Distinctive regional-specific PROS1 mutation spectrum in Southern China. 2018, 46:120-124.

11. Wypasek E, Potaczek DP, Plonka J, Alhenc-Gelas M, Undas A. Protein S deficiency and Heerlen polymorphism in a Polish patient with acute myocardial infarction and previous venous thromboembolism. Thromb Res. 2013;132:776-7.

12. Brouwer J, Lijfering W, Ten Kate $M$, Kluin-Nelemans $H$, Veeger $N$ van der. Meer JJT, haemostasis: High long-term absolute risk of recurrent venous thromboembolism in patients with hereditary deficiencies of protein S, protein C or antithrombin. 2009, 101:93-99.

13. Kumar P, Henikoff S, Ng PJNp. Predicting the effects of coding non-synonymous variants on protein function using the SIFT algorithm. 2009, 4:1073-1081.

14. Adzhubei I, Schmidt S, Peshkin L, Ramensky V, Gerasimova A, Bork P, Kondrashov A. Sunyaev SJNm: A method and server for predicting damaging missense mutations. 2010, 7:248-249.

15. Schwarz J, Cooper D, Schuelke M, Seelow D. MutationTaster2: Mutation prediction for the deepsequencing age. Nature methods. 2014;11:361-2.

16. Patnaik MM, Moll S. Inherited antithrombin deficiency: A review. Haemophilia: the official journal of the World Federation of Hemophilia. 2008;14:1229-39.

17. Liu S, Luo S, Yang L, Wang M, Jin Y, Li X, Xu QJH: Phenotypic and Genotypic Analysis of a Hereditary Antithrombin Deficiency Pedigree Due to a Novel SERPINC1 Mutation (p.Met281Thr). 2020, 40:687690. 
18. Schmidel D, Tatro A, Phelps L, Tomczak J, Long GJB. Organization of the human protein S genes. 1990, 29:7845-7852.

19. Suleiman L, Negrier C, Boukerche H. Protein S: A multifunctional anticoagulant vitamin K-dependent protein at the crossroads of coagulation, inflammation, angiogenesis, and cancer. Crit Rev Oncol Hematol. 2013;88:637-54.

20. Kim HJ, Seo JY, Lee KO, Bang SH, Lee ST, Ki CS, Kim JW, Jung CW, Kim DK, Kim SH. Distinct frequencies and mutation spectrums of genetic thrombophilia in Korea in comparison with other Asian countries both in patients with thromboembolism and in the general population. Haematologica. 2014;99:561-9.

21. Soare A, Popa C. Deficiencies of Proteins C, S and Antithrombin and Activated Protein C ResistanceTheir Involvement in the Occurrence of Arterial Thromboses. Journal of medicine life. 2010;3:412-5.

22. Xu J, Peng G, Ouyang Y. A novel mutation Gly222Arg in PROS1 causing protein S deficiency in a patient with pulmonary embolism. J Clin Lab Anal. 2020;34:e23111.

23. Caspers M, Pavlova A, Driesen J, Harbrecht U, Klamroth R, Kadar J, Fischer R, Kemkes-Matthes B, Oldenburg J. Deficiencies of antithrombin, protein $\mathrm{C}$ and protein $\mathrm{S}$ - practical experience in genetic analysis of a large patient cohort. Thromb Haemost. 2012;108:247-57.

24. Marlar R, Gausman, JJAjoh. Protein S abnormalities: a diagnostic nightmare. 2011, 86:418-421.

25. Alhenc-Gelas M, Plu-Bureau G, Horellou MH, Rauch A, Suchon P. group Ggt: PROS1 genotype phenotype relationships in a large cohort of adults with suspicion of inherited quantitative protein $S$ deficiency. Thromb Haemost. 2016;115:570-9.

26. Ding Q, Shen W, Ye X, Wu Y, Wang X. Wang HJBc, molecules, diseases: Clinical and genetic features of protein C deficiency in 23 unrelated Chinese patients. 2013, 50:53-58.

27. ten Kate M, van der Meer, JJHtojotWFoH. Protein S deficiency: a clinical perspective. 2008, 14:12221228.

28. Estellés A, Garcia-Plaza I, Dasí A, Aznar J, Duart M, Sanz G, Pérez-Requejo J, España F, Jimenez C, Abeledo G. Severe Inherited "Homozygous" Protein C Deficiency in a Newborn Infant. Thromb Haemost. 1984;52:53-6.

29. Burstyn-Cohen T, Heeb M, Lemke GJTJoci. Lack of protein S in mice causes embryonic lethal coagulopathy and vascular dysgenesis. 2009, 119:2942-2953.

30. Andersen B, Bisgaard M, Lind B, Philips M, Villoutreix B, Thorsen SJT. haemostasis: Characterization and structural impact of five novel PROS1 mutations in eleven protein S-deficient families. 2001, 86:1392-1399.

31. He X, Dahlback B. Molecular cloning, expression and functional characterization of rabbit anticoagulant vitamin-K-dependent protein S. European journal of biochemistry / FEBS. 1993;217:857-65.

32. Chu M, Sun J, Bird PJBeba. Cloning and sequencing of a cDNA encoding the murine vitamin Kdependent protein S. 1994, 1217:325-328. 
33. García de Frutos P, Fuentes-Prior P, Hurtado B. Sala NJT, haemostasis: Molecular basis of protein S deficiency. 2007, 98:543-556.

34. Sasaki T, Knyazev P, Cheburkin Y, Göhring W, Tisi D, Ullrich A, Timpl R, Hohenester EJTJobc. Crystal structure of a C-terminal fragment of growth arrest-specific protein Gas6. Receptor tyrosine kinase activation by laminin G-like domains. 2002, 277:44164-44170.

35. Ikejiri M, Tsuji A, Wada H, Sakamoto Y, Nishioka J, Ota S, Yamada N, Matsumoto T, Nakatani K, Nobori T, Itoh M. Analysis three abnormal Protein $\mathrm{S}$ genes in a patient with pulmonary embolism. Thrombosis research. 2010;125:529-32.

36. Nishi H, Shaytan A, Panchenko A. Physicochemical mechanisms of protein regulation by phosphorylation. Frontiers in genetics. 2014;5:270.

37. Humphrey SJ, James DE, Mann M. Protein Phosphorylation: A Major Switch Mechanism for Metabolic Regulation. Trends Endocrinol Metab. 2015;26:676-87.

38. Waterhouse A, Bertoni M, Bienert S, Studer G, Tauriello G, Gumienny R, Heer FT, de Beer TAP, Rempfer C, Bordoli L, et al. SWISS-MODEL: homology modelling of protein structures and complexes. Nucleic Acids Res. 2018;46:W296-303.

39. Sjöberg A, Trouw L, McGrath F, Hack C, Blom AJJoi. Regulation of complement activation by Creactive protein: targeting of the inhibitory activity of C4b-binding protein. 2006, 176:7612-7620.

40. D'Angelo A, D'Angelo S. Protein S deficiency. Haematologica. 2008;93:498-501.

41. Villoutreix B, Dahlbäck B, Borgel D, Gandrille S, Muller YJP. Three-dimensional model of the SHBG-like region of anticoagulant protein S: new structure-function insights. 2001, 43:203-216.

42. Reglińska-Matveyev N, Andersson H, Rezende S, Dahlbäck B, Crawley J, Lane D, Ahnström JJB. TFPI cofactor function of protein S: essential role of the protein S SHBG-like domain. 2014, 123:39793987.

43. Yamazaki T, Katsumi A, Kagami K, Okamoto Y, Sugiura I, Hamaguchi M, Kojima T, Takamatsu J, Saito $\mathrm{H}$. Molecular basis of a hereditary type I protein $\mathrm{S}$ deficiency caused by a substitution of Cys for Arg474. Blood. 1996;87:4643-50.

44. Reitsma $P$, Ploos van Amstel $H$, Bertina RJTJoci. Three novel mutations in five unrelated subjects with hereditary protein S deficiency type I. 1994, 93:486-492.

\section{Tables}

Table 1 Primers for qRT-PCR 


\begin{tabular}{|ll|}
\hline hPROS1 qRT F & CCCGGAAACGGATTATTTTT \\
\hline hPROS1 qRT R & CTCCTTGCCAACCTGGTTTA \\
\hline hGAPDH F & agaaggctggggctcatttg \\
\hline hGAPDH R & aggggccatccacagtcttc \\
\hline CopGFP qRT F & aggacagcgtgatcttcacc \\
\hline CopGFP qRT R & cttgaagtgcatgtggctgt \\
\hline
\end{tabular}

Table 2 Coagulation function indexs of proband and family members in hereditary protein S deficiency family

\begin{tabular}{|c|c|c|c|c|c|c|c|c|}
\hline Items & $\begin{array}{l}\text { Propositus } \\
(\llbracket 5)\end{array}$ & 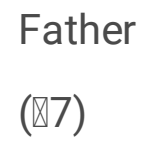 & $\begin{array}{l}\text { Mother } \\
(\varangle 8)\end{array}$ & 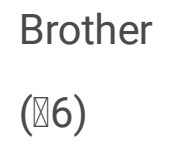 & $\begin{array}{l}\text { Member } \\
\text { (II1) }\end{array}$ & $\begin{array}{l}\text { Member } \\
\text { (II6) }\end{array}$ & 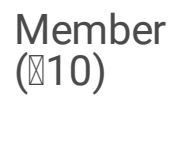 & $\begin{array}{l}\text { reference } \\
\text { value }\end{array}$ \\
\hline PT (s) & $13.3^{*}$ & 11.2 & $14.7^{*}$ & 12.3 & 9.8 & 11.9 & 12.1 & $9.9-12.9$ \\
\hline INR & $1.17 *$ & 0.89 & $1.37 *$ & 1.07 & 0.92 & 1.02 & 1.11 & $0.79-1.12$ \\
\hline $\begin{array}{l}\text { APTT } \\
\text { (s) }\end{array}$ & 27.9 & 26.4 & $101.6^{*}$ & 32 & 27.1 & 24.3 & 23.9 & 23.3-32.5 \\
\hline TT (s) & 15.5 & 15.8 & $60 *$ & $30.9 *$ & 17.1 & 16.4 & 19.2 & $14-21$ \\
\hline $\begin{array}{l}\mathrm{Fg} \\
(\mathrm{g} / \mathrm{L})\end{array}$ & 2.57 & 2.32 & $0.9^{\wedge}$ & 1.9 & 2.41 & 2.79 & 2.34 & $1.8-3.5$ \\
\hline $\begin{array}{l}\text { FDP } \\
\text { 『mg/L区 }\end{array}$ & $57.2^{*}$ & - & - & - & - & - & - & $0-5$ \\
\hline $\begin{array}{l}\text { D- } \\
\text { dimer }\end{array}$ & $25.8^{*}$ & 0.24 & $13.2^{*}$ & $15.5^{\star}$ & 0.23 & 0.01 & 0.01 & $0-0.55$ \\
\hline PS(\%) & $<16^{\wedge}$ & 84.4 & $<16^{\wedge}$ & $16.7^{\wedge}$ & 102.7 & 97.4 & 112.3 & $\begin{array}{l}\text { Male®75- } \\
130 \\
\text { Female区 } \\
52-118\end{array}$ \\
\hline PC(\%) & 66.9 & 90.1 & 100.2 & 60.2 & 113.4 & 124.2 & 98.1 & 70-140 \\
\hline AT- $\bigotimes(\%)$ & 92 & 107.6 & 97.4 & 85.9 & 121.2 & 109.1 & 97.1 & $75-125$ \\
\hline
\end{tabular}

Note: PT :prothrombin time; INR: international normalized ratio; APTT: activated partial thromboplastin

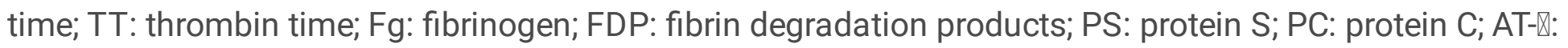
antithrombin $\bigotimes_{;} *$ : represents a significant increase; ${ }^{\wedge}$ : represents a significant decrease.

\section{Figures}




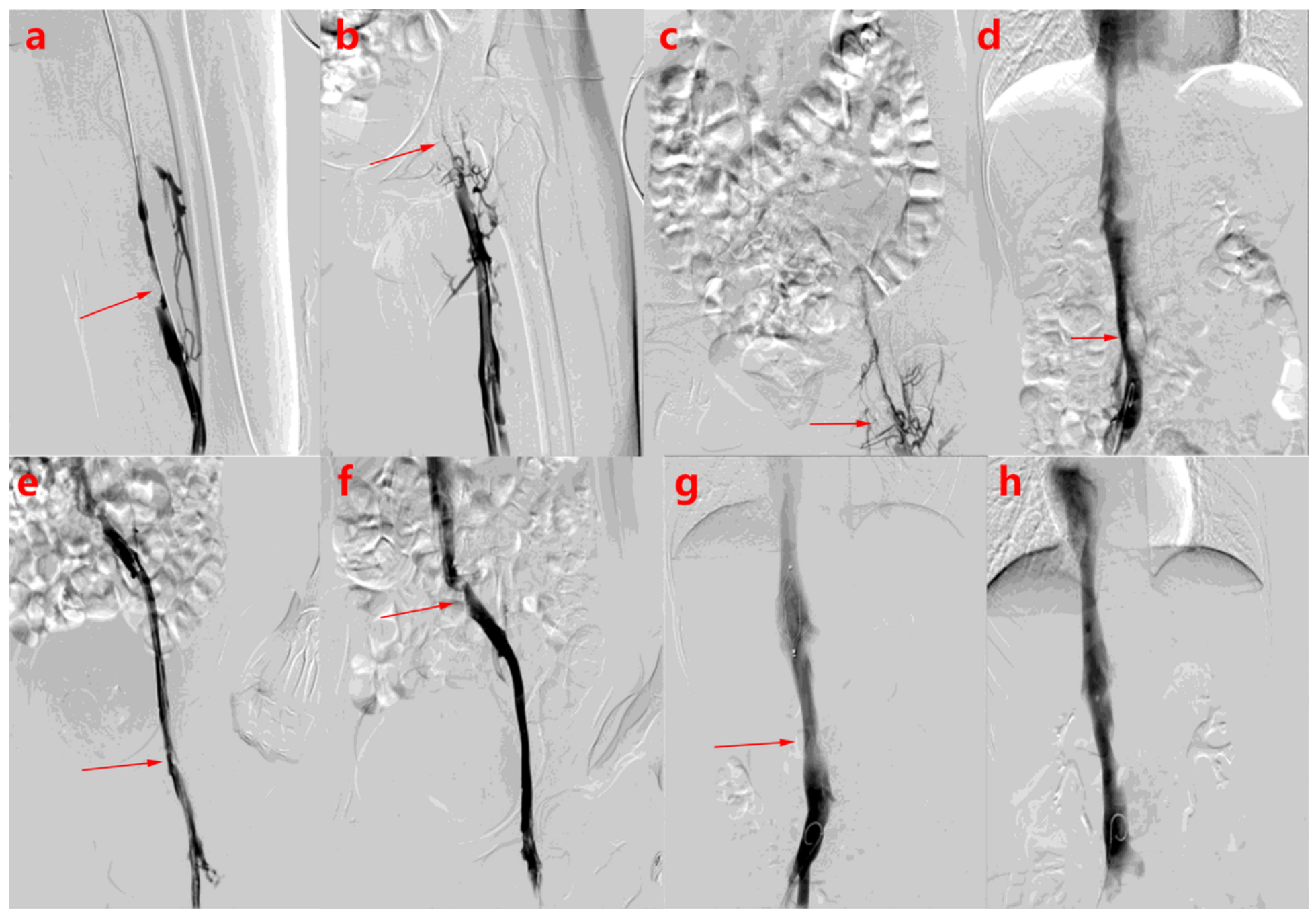

Figure 1

Digital subtraction angiography (DSA) of the proband (III5). (a) Proximal angiography of the left superficial femoral vein shows a filling defect without development. (b) The left iliac vein is not developed and some collateral vessels are observed. (c) The distal end of the inferior vena cava shows a filling defect and thrombosis in the left side wall. (d) After thrombolysis with 2 million units of urokinase, the left superficial femoral vein (e), left iliac vein $(f)$, and left wall of the distal inferior vena cava $(g)$ show no filling defect, and the thrombus is dissolved and absorbed. Angiographic picture after removal of the inferior vena cava filter $(\mathrm{h})$. 


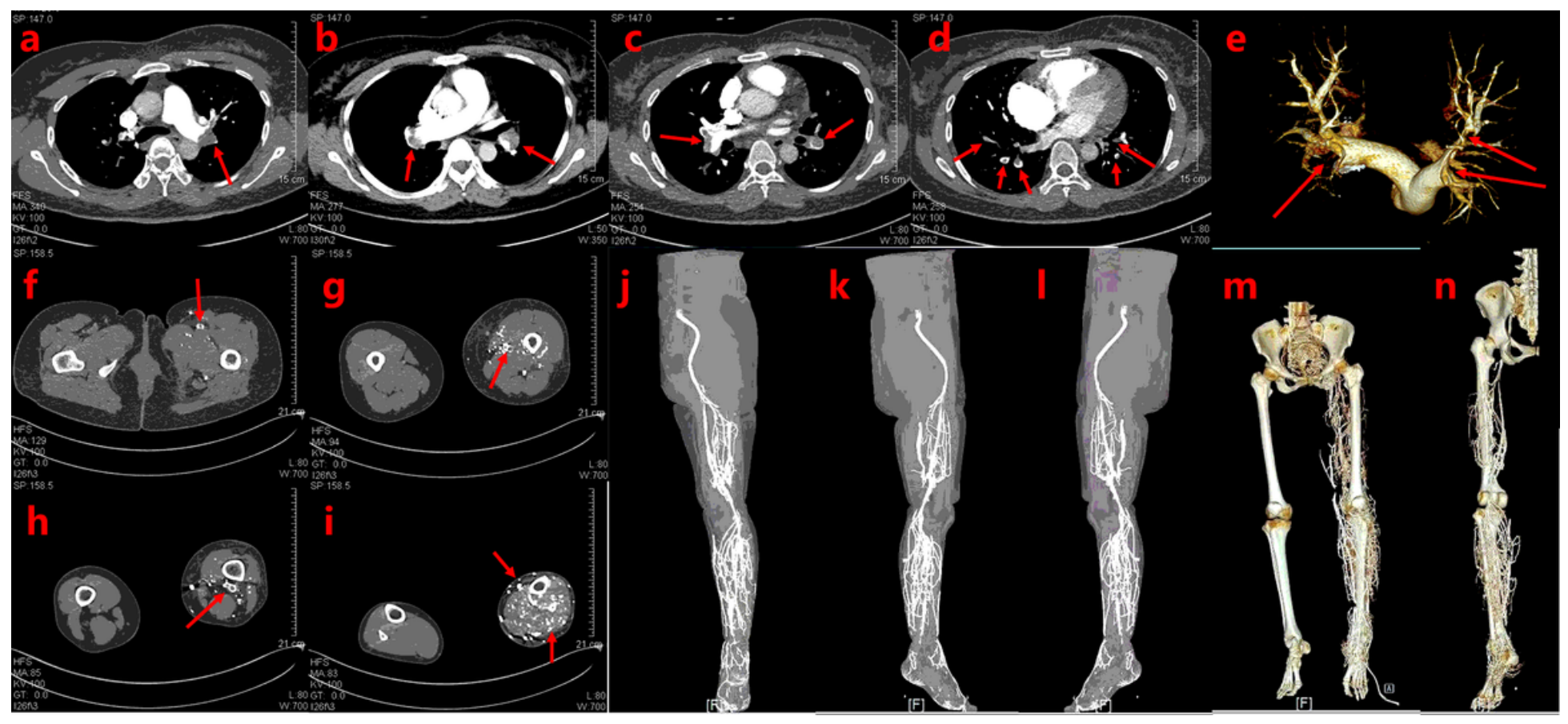

\section{Figure 2}

Computed tomographic angiography (CTA) of the mother of the proband (II8). CTA shows a low density filling defect in the left common iliac vein, external iliac vein, femoral vein, and popliteal vein. The contrast medium is narrowed at the local edge and passes through in a complete ring, surrounded by multiple collateral vessels with local reticulation. Multiple tortuous vessels are observed in the left leg, the deep veins of the lower extremities are not clearly displayed, and the soft tissue of the left lower extremities is swollen. Therefore, deep venous thrombosis of the lower extremities (Figure 4f-n) is considered. Low-density filling defects are observed locally in the distal end of the left and right pulmonary arteries and in the branches of both pulmonary arteries, suggesting pulmonary embolism (Figure 4a-e). 
a

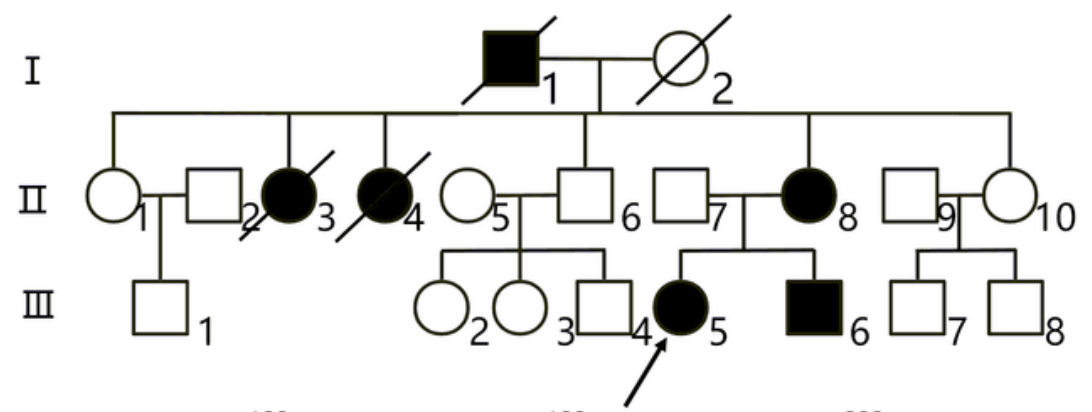

b

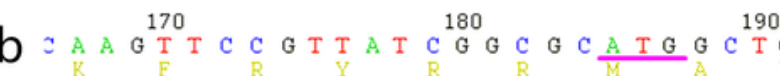

200
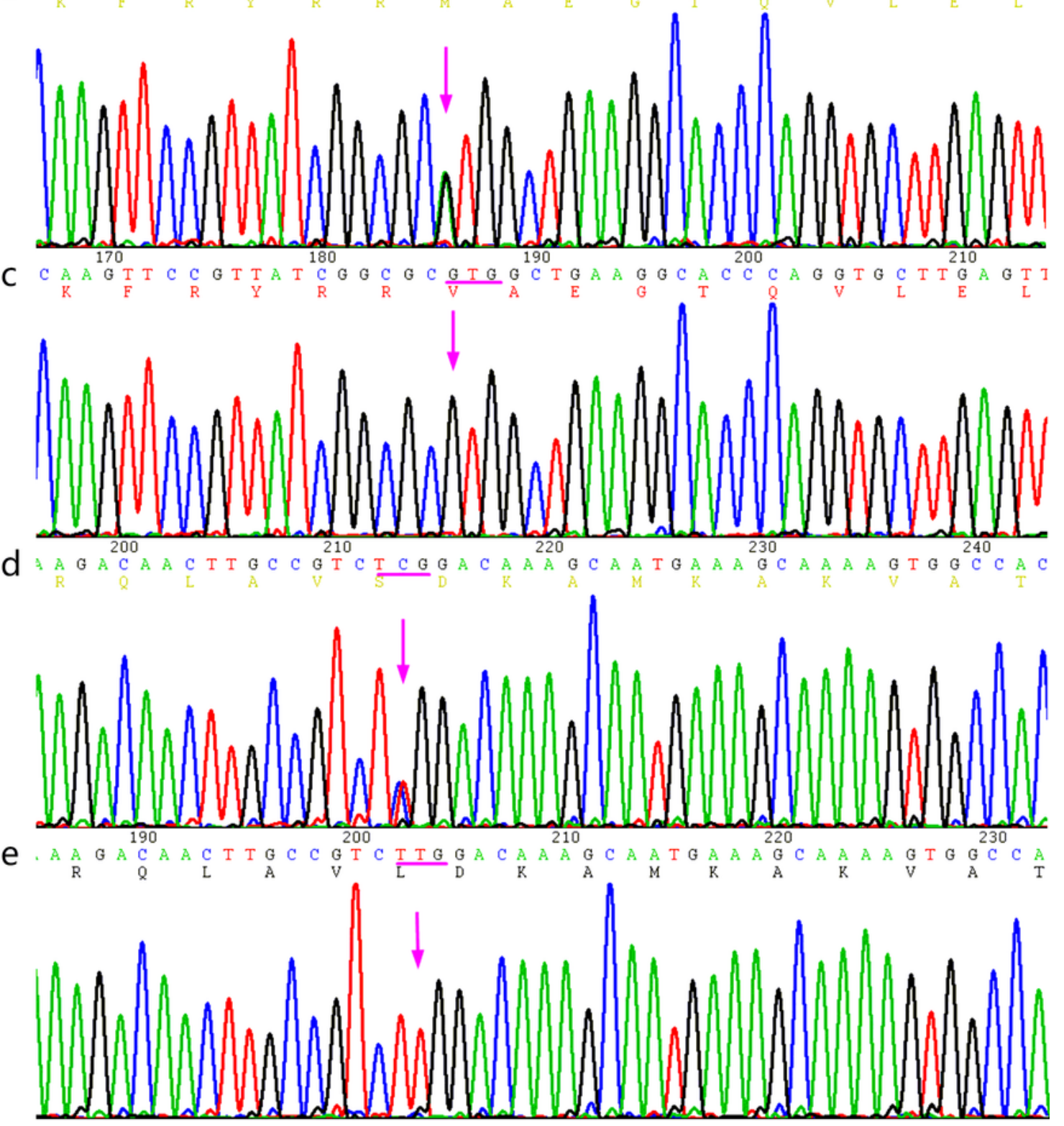

Figure 3

Depiction of the protein S (PROS1) and Serpin family C member 1 (SERPINC1) mutations. (a) In the family map of hereditary protein S deficiency, the proband (III5) and other patients carry a c. 1820T >C (p.Leu607Ser) PROS1 heterozygous mutation. (b) Mutation in SERPINC1, c.883G > A (p.Val295Met). (c) The corresponding SERPINC1 wild type sequence. (d) The C.1820T > C (p.Leu607Ser) PROS1 mutation. (e) The corresponding PROS1 wild type sequence. 
a

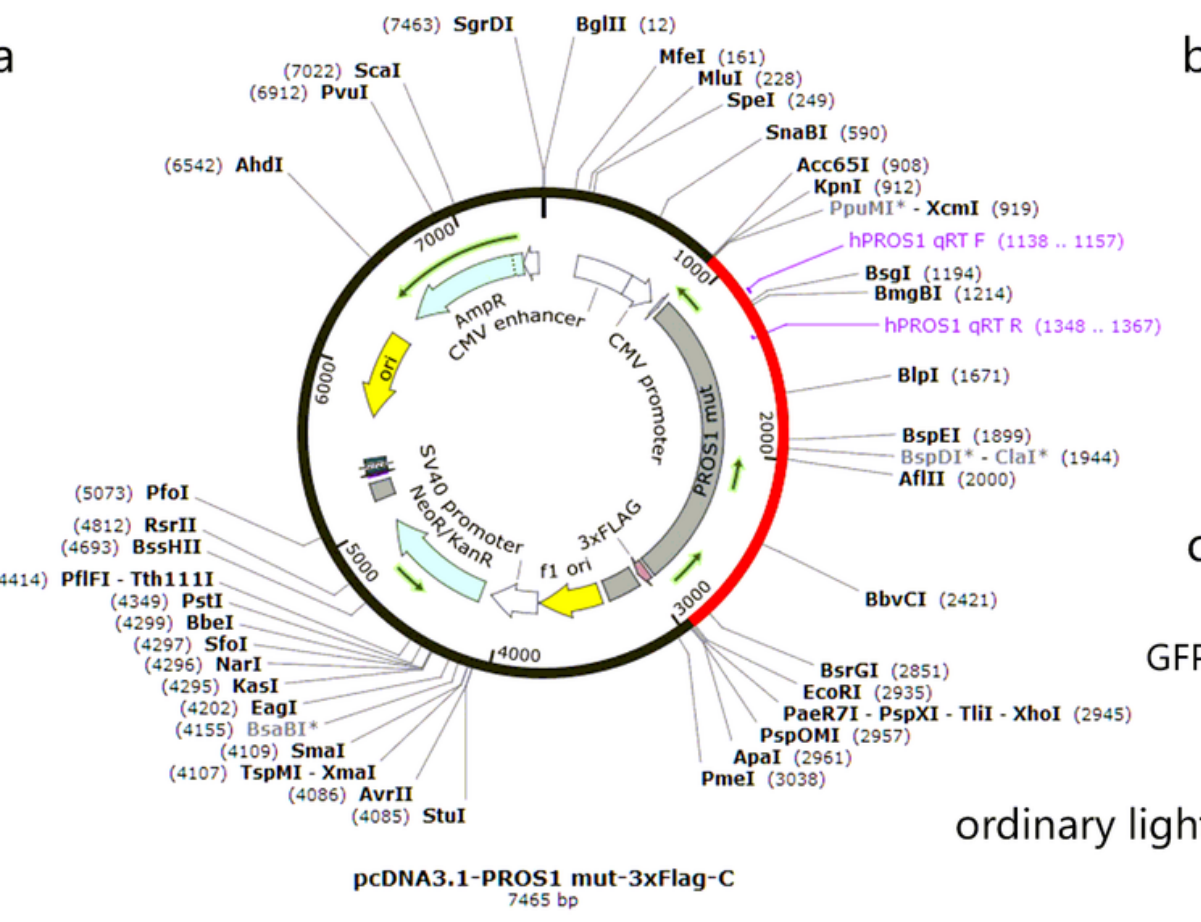

GFP b
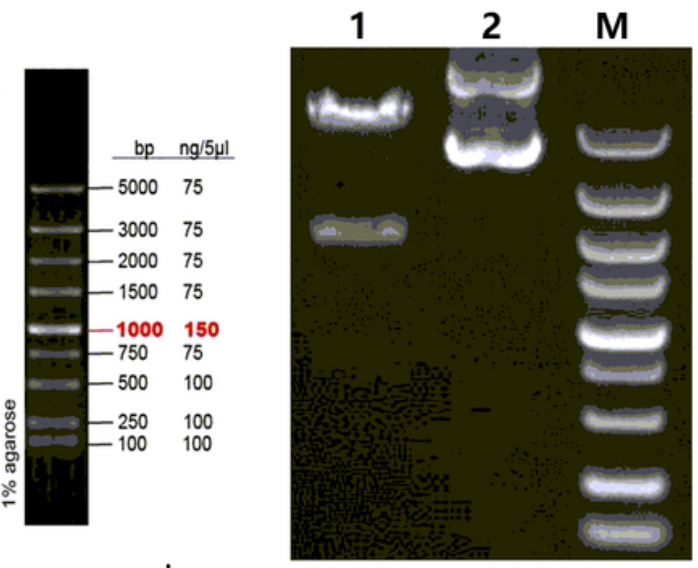

C mock PROS1 PROS1-mut

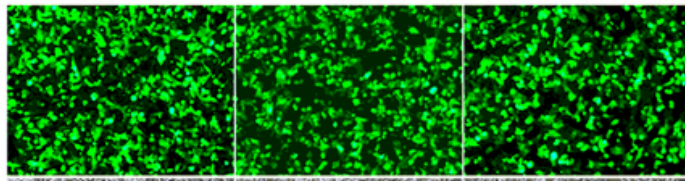

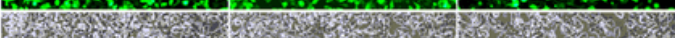
t.

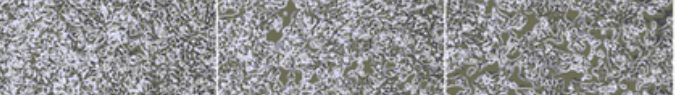

\section{Figure 4}

Protein S (PROS1) plasmid construction and verification. (a) Schematic diagram of the p.cDNA3.1PROS1 mut-3xFlag-C plasmid vector construction. (b) PROS1 and PROS1 (L607S) plasmids have been digested with $\mathrm{Kpnl} / \mathrm{Xhol}$ to determine whether the constructed plasmids are correct. Lane $\mathrm{M}$ is the DNA Marker, Lane 1 is plasmid digested with $\mathrm{Kpnl} / \mathrm{Xhol}$, and Lane 2 is plasmid DNA. (c), There is no significant difference in cell growth after transfection and green fluorescent protein (GFP) transfection efficiency among different groups. 


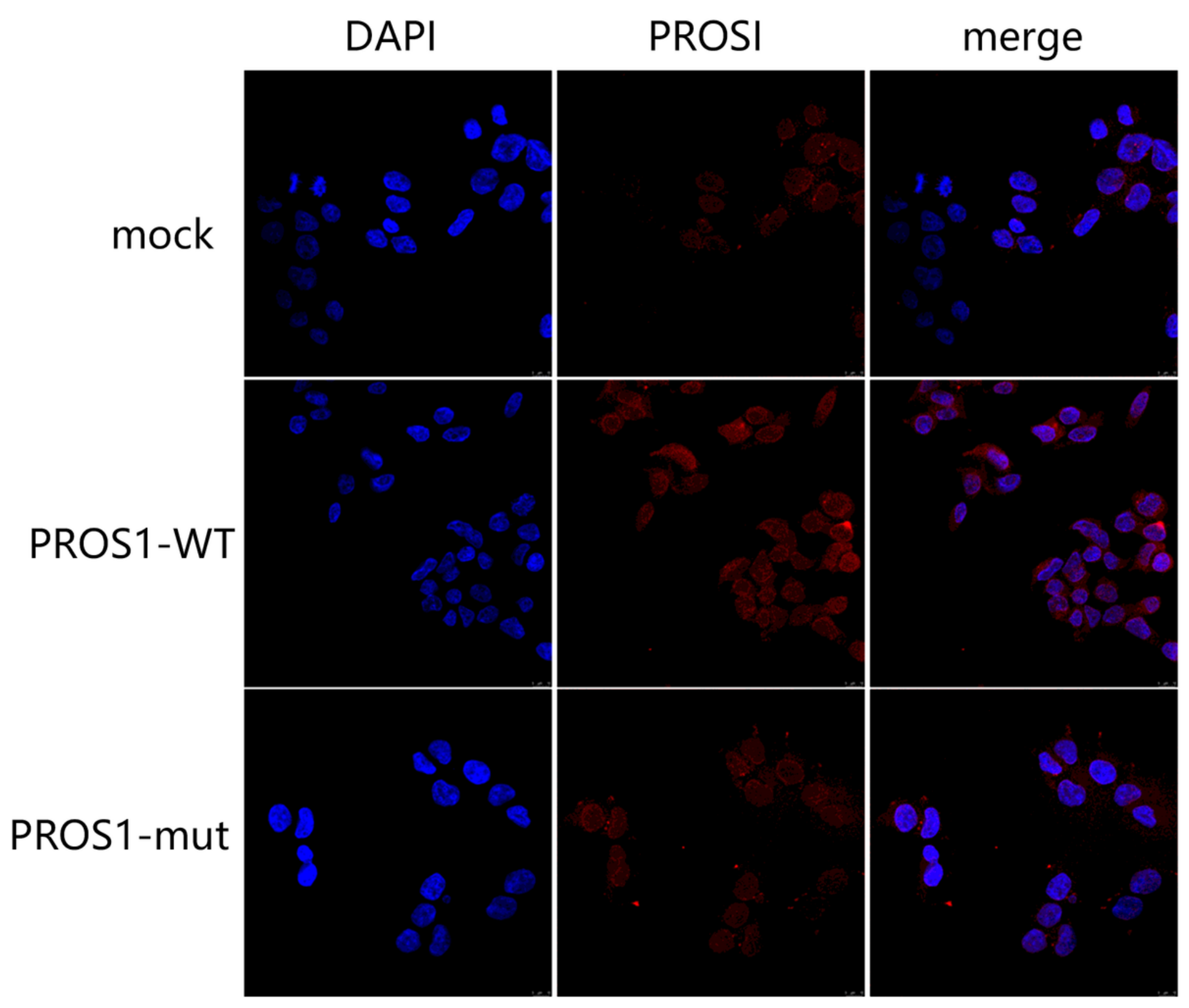

Figure 5

Localization of protein S (PROS1). Localization of PROS1 mock, wild type (PROS1-WT), and the p.Leu607Ser mutation (PROS1-M) in HEK293T cells, as detected by immunofluorescence. There is no difference before and after introduction of the PROS1 1820T > C mutation. PROS1 is mainly distributed in the cell interior. 
a

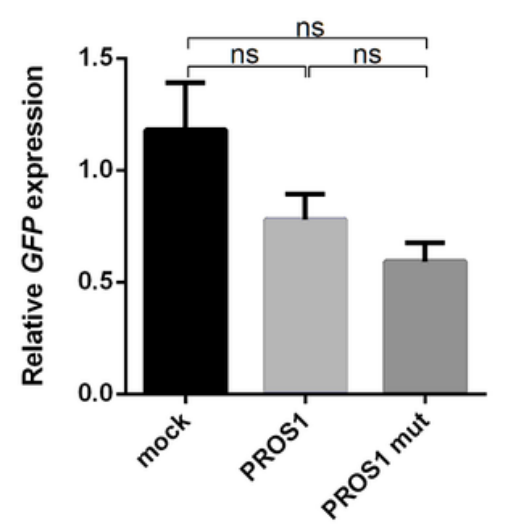

b

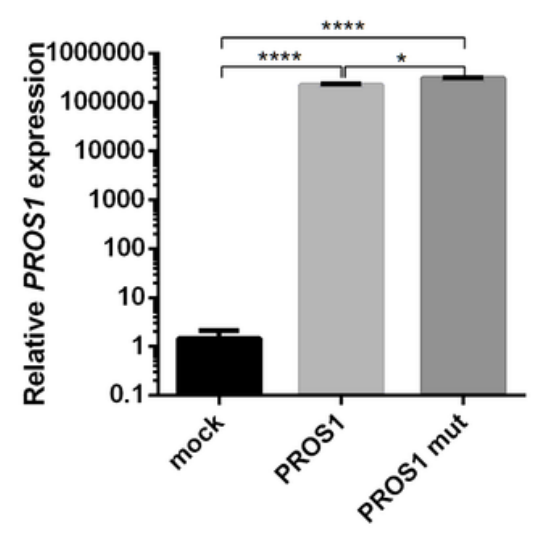

d

Cell supernatant

mock

PROS1

PROS1 mut

Cell Lysates

$\beta$-action

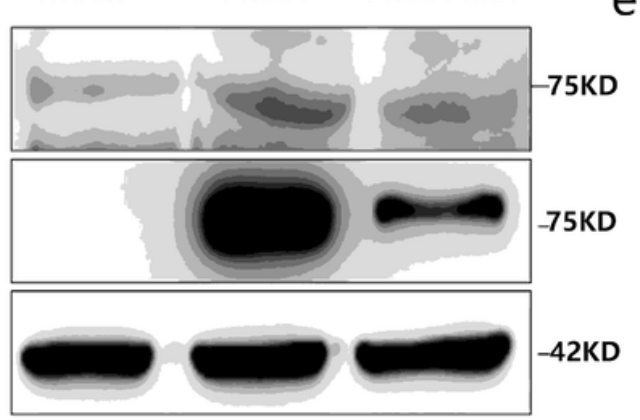

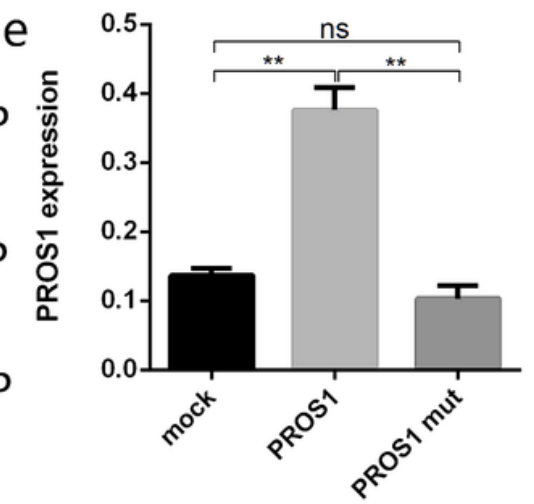

C
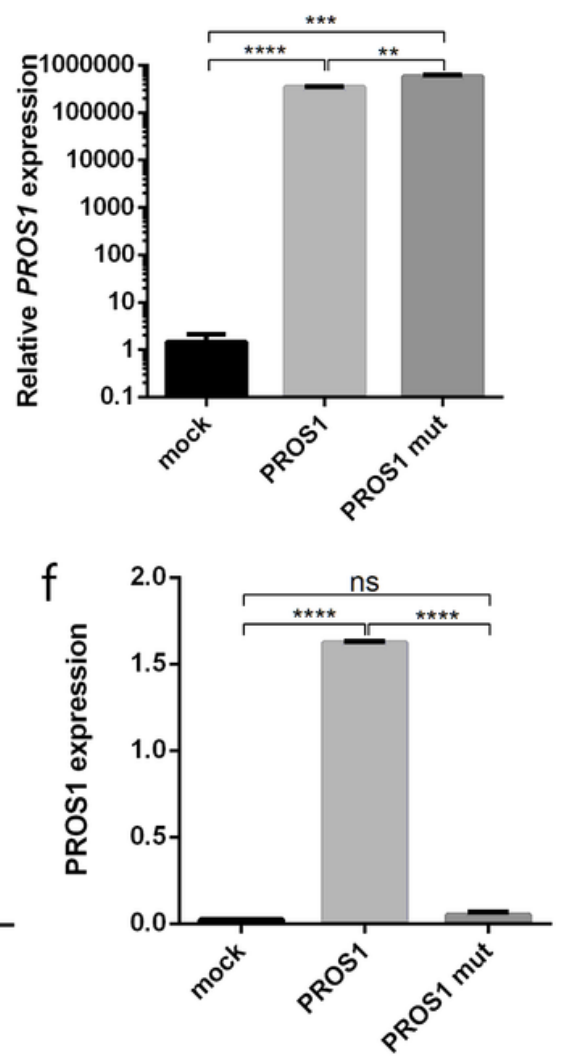

Figure 6

Relative protein S (PROS1) mRNA and protein expression. (a) Relative green fluorescent protein (GFP) expression of cells transfected with mock, wild type (PROS1-WT), and the p.Leu607Ser mutation (PROS1$M)$ shows that there is no significant difference in transfection efficiency between the three groups. (b) Relative PROS1 mRNA expression of mock, PROS1-WT, and PROS1-M in HEK293T cells with glyceraldehyde-3-phosphate dehydrogenase (GAPDH) as an internal reference. (c) Relative PROS1 mRNA expression of mock, PROS1-WT, and PROS1-M in HEK293T cells using GFP as an external reference. (d) PROS1 expression of mock, PROS1-WT, and PROS1-M in the supernatant and lysate of HEK293T cells, as detected by western blot. (e) According to the enzyme-linked immunosorbent assay (ELISA) standard curve, the expression of PROS1 mock, PROS1-WT, and PROS1-M in the supernatant of HEK293T cells is calculated. (f) According to the ELISA standard curve, the expression of PROS1 mock, PROS1-WT, and

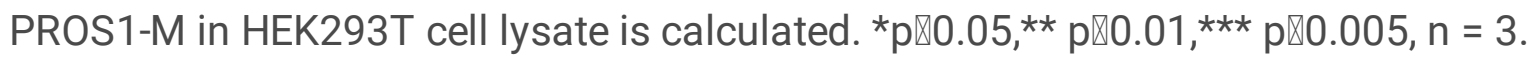


A

B

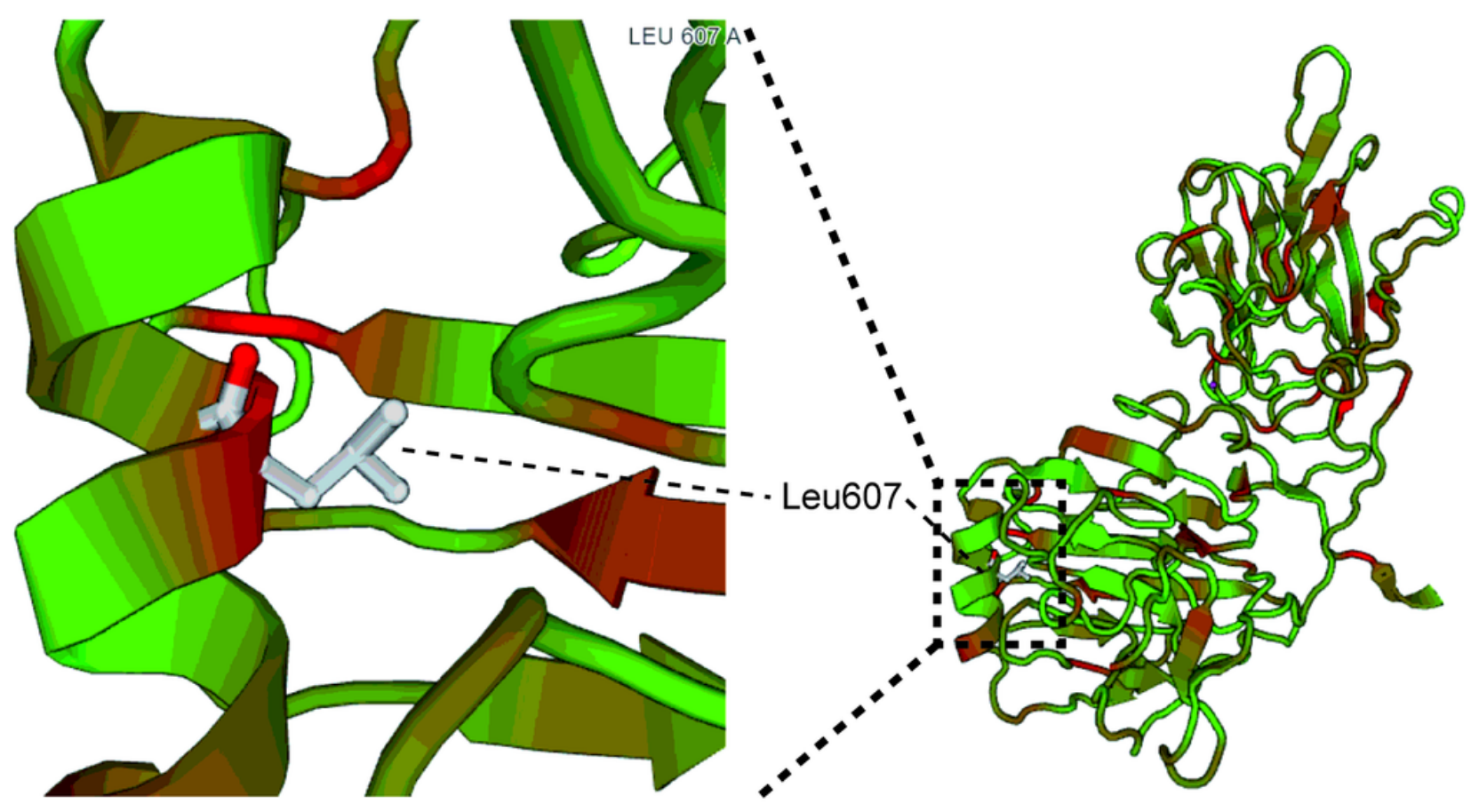

Homo sapiens

Pan troglodytes

Mus musculus

Hyaena hyaena

Ochotona curzoniae

Myotis

Halichoerus grypus
579 VNRNNLELSTPLKIETISHEDLQRQLAVLDKAMKAKVATYLGGLPDVPFSATPV 448 VNRNNLELSTPLKIETISHEDLQRQLAVLDKAMKAKVATYLGGLPDVPFSATPV 71 VNRNGLELWTPLRKDVIYSKDLQRQLAVLDKAMKRTVATYLGGIPDISFSATPV 578 VNRTNLELLTPLKKDIIYSEALQSQLAILDKAMKGTVATYLGGLPDIPFSATPV 578 VNRNNLDMSTPLRKDAIHSDDLQSQLAVLDRAMRGTVTTYLGGLPDVPFNATPV 614 INRTNLELVTPLKYDIIYSEDLQREFGILDKAMKGKVATYLGGLPVVPFSATPV 578 VNRNNLELFTPLKKDIXSSENLQGQLAILDKAMKGTVTTYLGGLPDIPFSATPV
632 501 124 631 631 667 631

\section{Figure 7}

Protein S (PROS1) homology modeling and analysis. (a) Homology modeling of PROS1 has been performed using Swiss-Model. Leu607 is labeled in the alpha helix. (b) Conserved analysis of amino acid sequences near Leu607 (marked with red) (https://swissmodel.expasy.org/repository/uniprot/P07225? template $=1 \mathrm{~h} 30.1$. A\&range $=266-673)$. 